\title{
Pulmonary hydatidosis genotypes isolates from human clinical surgery based on sequencing of mitochondrial genes in Fars, Iran
}

\author{
Parviz Mardani ${ }^{1,2}$ (D), Ali Talebi Ezabadi ${ }^{1}$, Bahareh Sedaghat ${ }^{3}$ (D) and Seyed Mahmoud Sadjjadi ${ }^{3^{*}}$ (D)
}

\begin{abstract}
Background: Cystic echinococcosis (CE)/hydatidosis is an important neglected parasitic zoonotic disease caused by the metacestode of Echinococcus granulosus s.l. The present study was designed to identify the pulmonary CE species/genotypes in isolated human underwent to surgery in our center in Southern Iran.

Methods: The study population of this study were all patients in Fars province who were admitted to Namazi Hospitals for pulmonary hydatid cyst surgery. Thoracic surgery was performed in the thoracic ward and the cyst/s was removed by open surgery via posterolateral or lateral thoracotomy. DNA was extracted from the germinal layer or the protoscoleces. PCR technique was performed using the cytochrome C oxidase subunit1 (cox1) gene, and the products were sequenced.

Results: A total of 32 pulmonary hydatid cyst samples were collected from 9 (28\%) female and 23 (72\%) male aged from 4 to 74 years old. A total of $18(56 \%)$ cyst/s were in the left lobe and $14(44 \%)$ cysts in the right lobe. Sequence analysis of the cysts showed that 24 samples (75\%) were E. granulosus S.s (G1-G3) genotype and 8 (25\%) were E. canadensis (G6/G7) genotype.

Conclusion: E.granulosus s.s genotype was the most prevalent genotype followed by E. canadensis (G6/G7) genotype. There was no significant statistical correlation between cysts' size, location, genotype strain, and patients' age and gender.
\end{abstract}

Keywords: Hydatid cyst, Genotype, Iran, Pulmonary

\section{Background}

Cystic Echinococcosis (CE), also known as hydatid disease or hydatidosis, is a neglected zoonotic disease. Canids are the definitive hosts of the parasite and various ungulates as its intermediate hosts [1]. Human infection is caused by the ingestion of the eggs of Echinococcus granulosus s.l. leading to the formation of larval stage in

\footnotetext{
* Correspondence: smsadjiadi@sums.ac.ir

${ }^{3}$ Department of Parasitology and Mycology, School of Medicine, Shiraz University of Medical Sciences, Shiraz, Iran

Full list of author information is available at the end of the article
}

the human body [1]. The liver is the most commonly affected organ (about $70 \%$ of cases) and the lungs are the second most commonly affected organ (about 20\% of cases). In $85-90 \%$ of CE cases, only one organ is affected, and greater than $70 \%$ of cases have only one cyst [2,3]. There are currently nine species of Echinococcus.; four of them have been known to cause public health concern, which includes Echinococcus granulosus s.l. causing cystic echinococcosis, Echinococcus multilocularis producing alveolar echinococcosis, and Echinococcus vogeli and Echinococcus oligarthrus resulting in

C C The Author(s). 2021 Open Access This article is licensed under a Creative Commons Attribution 4.0 International License, which permits use, sharing, adaptation, distribution and reproduction in any medium or format, as long as you give appropriate credit to the original author(s) and the source, provide a link to the Creative Commons licence, and indicate if changes were made. The images or other third party material in this article are included in the article's Creative Commons licence, unless indicated otherwise in a credit line to the material. If material is not included in the article's Creative Commons licence and your intended use is not permitted by statutory regulation or exceeds the permitted use, you will need to obtain permission directly from the copyright holder. To view a copy of this licence, visit http://creativecommons.org/licenses/by/4.0/. The Creative Commons Public Domain Dedication waiver (http://creativecommons.org/publicdomain/zero/1.0/) applies to the data made available in this article, unless otherwise stated in a credit line to the data. 
polycystic echinococcosis. Furthermore, two new species have lately been known: Echinococcus shiquicus and Echinococcus felidis [4-6]. E. granulosus sensu lato consist of 5 species of which 4 (E. granulosus s.s., E. equinus, $E$. ortleppi, and E. canadensis) are responsible for human CE (E. ortleppi and E. equinus to a far lesser extent, but they infected humans after all) with $E$. multilocularis, $E$. oligarthrus, and E.vogeli there are 7 species causing disease in human.

Recent advances in phylogenetic systematics have resulted in the recognition of nine species of Echinococcus: E. granulosus sensu stricto (G1 to G3), E. equinus (G4), E. ortleppi (G5), E. canadensis (G6 to G10), E. multilocularis, E. vogeli, E. oligarthrus, E. felidis, and E. shiquicus [5].

The most important etiological agents of human CE are E. granulosus s.s. and E. canadensis, both of which were formerly included in the species complex of $E$. granulosus s.l [7]. Different species and genotypes including E. granulosus s.s, E. canadensis, E. ortleppi have been reported from humans and animals from Iran [810]. CE can present various clinical manifestations depending on the location of involvement [11]. In pulmonary hydatidosis, the lower lobes are more frequently affected than the upper ones, and one in five cases is bilateral. The scale varies from 1 to $20 \mathrm{~cm}$ and the lung tissue is the organ where the hydatid cyst will become the largest due to simple compressibility. Lung cysts will stay asymptomatic and thus quiet for years, emerging for imaging or other purposes until chest X-rays are required. Coughing, discomfort, chest pain, fever, and hemoptysis are the initial symptoms. The development of an anaphylactic reaction and the appearance of vomiting are indicative of the rupture of the cyst. In this latter case, the direct study of sputum will show the presence of E. granulosus s.l. hooklets. When confronted with an initial thoracic hydatid cyst, it is mandatory to preclude the presence of a liver location [12]. The preliminary growth of the hydatid disease of the lung or lung echinococcosis is asymptomatic and some symptoms, such as chest pain, cough, fever, dyspnea, or allergic reaction, hemoptysis may appear $[13,14]$.

Human CE is treated by a variety of pharmacological and surgical methods ranging from chemotherapeutic treatment with albendazole and minimally invasive surgical treatments like PAIR (percutaneous Puncture, Aspiration, Injection, and Reaspiration) in asymptomatic patients $[15,16]$. There are various surgical procedures for pulmonary hydatid disease like enucleation, pericystectomy, cystostomy with capitonnage, cystostomy with the closure of the bronchial openings, and capitonnage, cystotomy with the closure of bronchial openings alone, open aspiration by Figuera technique, segmental resection, and lobectomy [17, 18]. Currently, the most accepted surgical procedure for lung pulmonary is cystostomy methods that including intact cyst enucleation or removal after needle aspiration by maintaining the lung parenchyma as much as possible [14, 19-21].

$\mathrm{CE}$ is most commonly associated with the liver [22]. On the other hand, certain echinococcus species appear to have a predilection for other organ systems. This has been shown by the studies in Iran and Mongolia where the cases of brains have been reported to be caused primarily by $E$. canadensis(G6) [23, 24]. This may indicate that certain $E$. canadensis variants have brain or liver predilections [24]. These studies show that the molecular identification of the causative species is essential.

Different genotypes of E. granulosus s.l. have been identified from different organs based on molecular works in the world $[4,7,23]$. Numerous molecular studies on human isolates of $E$. granulosus s.l. have recognized the genotypes G1, G3, and G6 in different regions of Iran [9, 23, 25-27].

Iran remains one of the endemic countries for hydatid disease [28] and CE is responsible for $1 \%$ of surgery ward admissions in Iran [29]. Genotyping of human hydatid cyst is useful because it provides data about the transmission patterns of the Echinococcus $s p$. and information on the predominant prevalence of special genotypes in humans. It can also provide valuable information in the design of human hydatidosis control strategies $[29,30]$.

On the other hand, the most prevalent genotypes of human CE in Iran have been reported to be G1 and G6 $[9,31,32]$. This study was aimed to evaluate genotypes diversity of isolated human lung hydatid cysts based on mitochondrial genetic sequencing and find out the most prevalent species/genotype of pulmonary hydatidosis in Fars Province, Southern Iran.

\section{Methods \\ Sample collection}

A total of 32 patients with lung CE from different counties of Fars province, southern Iran (Fig. 1), who had been referred to different hospitals affiliated to Shiraz University of Medical Sciences, Shiraz, Iran were operated on during 2017-2019 (Figs. 2 and 3). Clinical and demographical features of the patients were collected, using the patients' hospital records. Lungs cysts were collected and transferred to the Helminthology Research Laboratory at the School of Medicine, SUMS, Iran. A part of the cysts was sent to the pathology section for CE confirmation. This study was approved by the Ethics Committee of Shiraz University of Medical Sciences (Code: IR.SUMS.MED.REC.1397.531). Informed consent was obtained from all individual participants included in the study. Patients were informed of the study objectives 


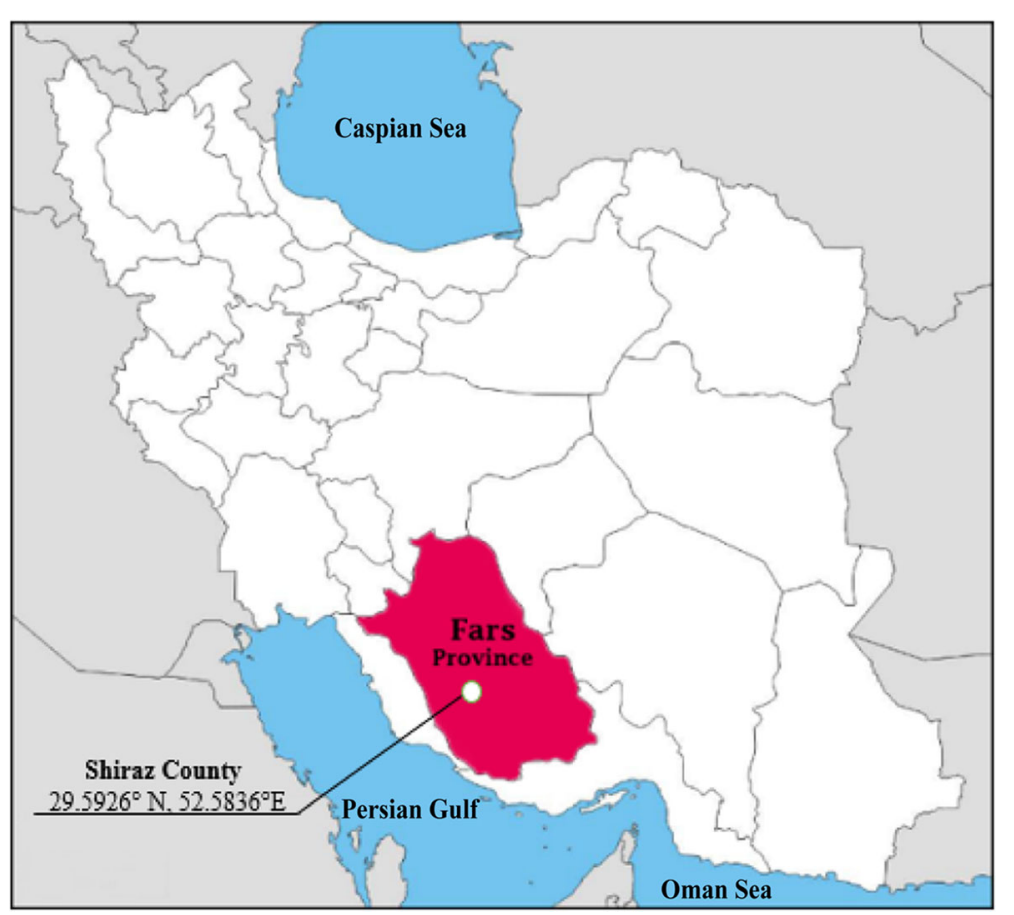

Fig. 1 Iran map showing the situation of Fars province

and gave written informed consent for tissue samples to be used for research.

\section{Surgical procedures}

The applied surgical procedure was open surgery via posterolateral or lateral thoracotomy. The method of surgery was performed based on cyst properties. In patients with an intact cyst, after wrapping the pleural cavity with lap sponge soaked with hypertonic saline, the suction of the cyst fluid was carried out with an angiocatheter, and subsequently enucleation of the laminated layer of the cyst, followed by closing the bronchial opening by vicryl suture. Also, capitonnage was performed accordingly.

In cases of ruptured cysts and the involvement of pleural cavity and peel formation, decortication of the cyst was performed followed by enucleation or wedge resection. Lobectomy was performed in cases in which consolidation of the lung parenchyma was observed. In cases in which the cyst was located in the periphery of the lung parenchyma, wedge resection was performed without any manipulation of the cyst. Furthermore, in patients with bilateral cysts, the operation was carried out in two stages with a 4-week interval, and the first stage was performed on the larger and intact cyst. Chest

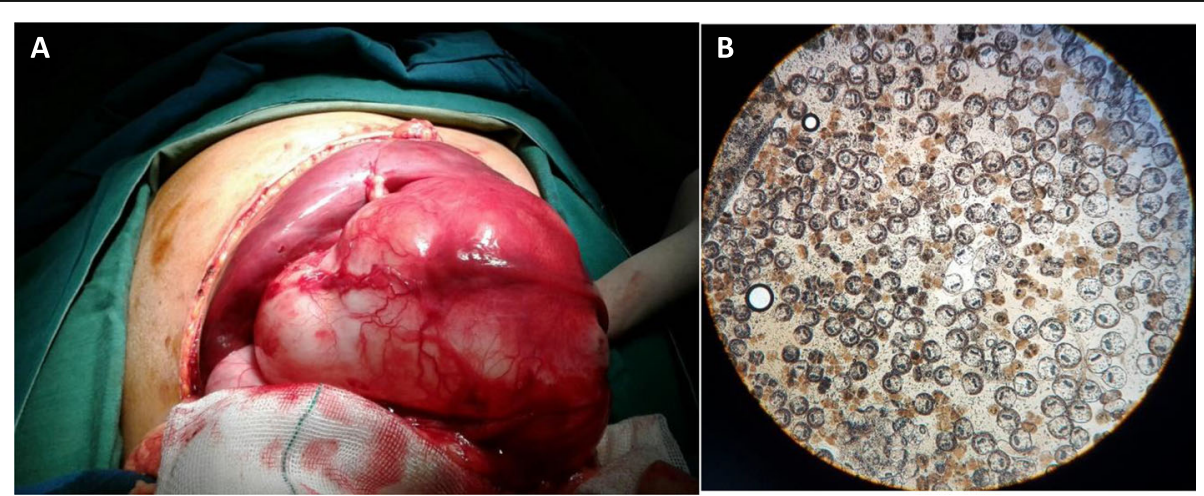

Fig. 2 A: Surgery of pulmonary hydatid cyst B: Protoscoleces of pulmonary hydatid cyst 


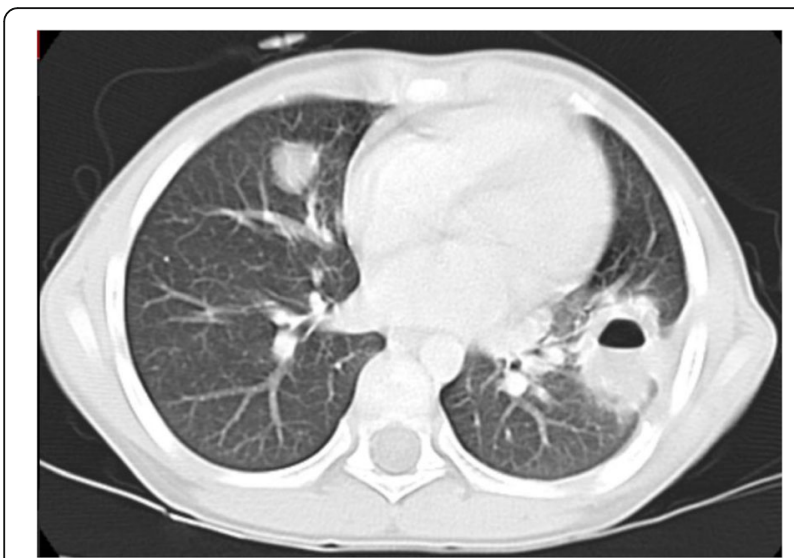

Fig. 3 computed tomography of pulmonary hydatid cyst in in base of left lower lobe

tube was inserted in all patients accordingly, which was removed after 4 to 5 days.

\section{DNA extraction and PCR amplification}

DNA was extracted from the germinal layers of the cyst/ s using a commercial DNA extraction kit (Yekta Tajhiz Azma, Iran), PCR, targeting cox1 genes, which was performed according to previous work procedures [33].

A $446 \mathrm{bp}$ of the partial region of the cox 1 gene was amplified for each extracted DNA.

The Cytochrome c oxidase subunit 1 ( $\operatorname{cox} 1)$ gene was amplified by two primers as follows: JB3 $\left(5^{\prime}\right.$-TTTT TTGGGCATCCTGAGGTTTAT-3') and JB4.5 (5'TAAAGAAAGAACATAATGAAAATG-3') for cox 1 gene as forward and reverse primers, respectively (35). PCR was performed in a final volume of $50 \mu$ l, including $2.5 \mu$ l genomic DNA, $3.5 \mathrm{mM} \mathrm{MgCl} 2,250 \mu \mathrm{M}$ of dNTPs, $25 \mathrm{p}$ mol. of each primer and $2 \mathrm{U}$ of Taq polymerase. The temperature profile was used for DNA amplification as follows: 40 cycles of $94{ }^{\circ} \mathrm{C}$ for $45 \mathrm{~s}, 51^{\circ} \mathrm{C}$ for $35 \mathrm{~s}$, $72{ }^{\circ} \mathrm{C}$ for $45 \mathrm{~s}$, followed by a final extension at $72{ }^{\circ} \mathrm{C}$ for $10 \mathrm{~min}$. PCR products were visualized using electrophoresis with $1.5 \%$ agarose gel in TAE buffer and stained with GelRed (Biotium ${ }^{\circ}$ ). A 100-bp molecular ladder was used as DNA size marker in each gel for estimating the size of the bands. Gels were observed and photographed using a UV-trans illuminator $\left(\mathrm{Uvitec}^{\circ}\right)$.A purification kit (Vivantis ${ }^{\circ}$ ) was used for PCR primary products $\operatorname{cox} 1$ gene purification followed by sequencing in two directions using the similar forward and reverse primers applied in the PCR.

\section{Sequencing and phylogenetic analysis}

PCR products were sequenced by Bioneer Corporation (South Korea). Using BioEdit, the sequenced genes were edited to equal lengths for the phylogenetic analysis and using the BLAST program of GenBank, the obtained sequences were aligned and compared.

A Phylogenetic tree was drawn using our sequences and reference sequence obtained from GenBank. The maximum likelihood tree was constructed based on the Tamura-Nei model, using the MEGA5 software [34]. Taenia saginata was considered as, theoutgroup in the model.

\section{Results}

Demographic characteristics of patients

A total of 9 out of 32 patients (28\%) patients were female and 23 out of 32 (72\%) were male. Patients' age ranged from 4 to 78 years and the mean age was 31.8 $(\mathrm{SD}=20.28)$ years $($ Table 1$)$.

\section{Characteristics of the cysts}

According to the location of the pulmonary hydatid cysts: The cyst of a total of 18 cases (56\%), was in the left lobe, and in 14 cases (44\%) the cysts were in the right lobe. The cysts' size was classified as small (0-4 $\mathrm{cm})$, medium $(5-9 \mathrm{~cm})$, and large $(10-15 \mathrm{~cm})$. Among all operated hydatid cysts, 17 (53\%) were small, 2 (6\%) were large and $13(41 \%)$ of them were medium size (Table 1). Figure 3 demonstrates a radiological image of pulmonary hydatid cyst.

PCR, nucleotide sequence analysis and phylogenetic analysis

The PCR products showed a specific band of $446 \mathrm{bp}$. The PCR products were sequenced using the same primer as PCR. Blast analysis showed a total of 24 out of 32 isolates $(755 \%)$ to be E. granulosus s.s.(G1-G3). A total of 8 out of 32 isolates (25\%) were E. canadensis (G6/ G7). The sequenced genes in this study were deposited in the GenBank under the accession numbers from MW350092 to MW350101.

The amplified genes and the accession numbers for the detected genotypes and other genotypes used for comparison are shown in Table 2. Taenia saginata with GenBank accession number MT535753 and Echinococcus granulosus strain G6 cytochrome oxidase subunit I gene with GenBank accession numbers: KC415063, were used as out groups in the phylogenetic trees, respectively. Phylogenetic tree construction showed the relationships between the isolates from the present study and the reference sequences from $E$. granulosus s.l. genotypes and other species (Fig. 4).

Statistical analysis showed no significant correlation between the genotype strains and the patients' gender, age, and also the involving lung lobe and cyst size. Table 1 shows the diversity and distribution of different strains based on various demographic and clinical features of the patients. 
Table 1 Distribution of various species/ genotypes of pulmonary hydatid cyst based on patients' demographic and clinical information

\begin{tabular}{|c|c|c|c|}
\hline Variable & Echinococcus species / genotypes (G1-G3), $n$ (\%) & Echinococcus species / genotypes (G6/G7), $n$ (\%) & Total $(\%)$ \\
\hline \multicolumn{4}{|l|}{ Age (years) } \\
\hline$\leq 20$ & $8(23)$ & $3(9)$ & $11(34.5)$ \\
\hline $21-40$ & $6(19)$ & $4(12.5)$ & $10(31.5)$ \\
\hline $40-60$ & $8(25)$ & $0(0)$ & $8(25)$ \\
\hline$>60$ & $3(7)$ & $1(3)$ & $3(9)$ \\
\hline \multicolumn{4}{|l|}{ Gender } \\
\hline Male & $18(56.5)$ & $5(15.5)$ & $23(72)$ \\
\hline Female & $6(19)$ & $3(9)$ & $9(28)$ \\
\hline \multicolumn{4}{|l|}{ lung lobe } \\
\hline Left & $15(47)$ & $3(9)$ & $18(56)$ \\
\hline Right & $9(28)$ & $5(16)$ & $14(44)$ \\
\hline \multicolumn{4}{|l|}{ Size of cyst } \\
\hline Small & $11(34)$ & $6(19)$ & $17(53)$ \\
\hline Medium & $11(34.5)$ & $2(6.5)$ & $13(41)$ \\
\hline Large & $2(6)$ & $0(0)$ & $2(6)$ \\
\hline Total (\%) & $24(75)$ & $8(25)$ & $32(100)$ \\
\hline
\end{tabular}

\section{Discussion}

Cystic echinococcosis/hydatidosis, as a zoonotic disease, involves patients worldwide and causes many related economical and public health consequences annually [38]. The disease is also known as a major endemic disease in Iran, where sheep, goats, and cattle, are still slaughtered traditionally and corpses wastes are simply available for stray dogs and other wild animals [39]. Since Namazi Hospital is a referral thoracic surgery center in the south of Iran and a large number of patients in Fars province and surrounding provinces with pulmonary hydatid cysts are admitted there, the present study aimed to evaluate the genotypes of isolated lung cysts, based on the sequencing of mitochondrial genes, in Fars province.

E.granulosus s.l.species has an extensive variety in the host and geographical distribution by diversity as high as
10 different well-known genotypes globally [22, 38]. Currently genotypes of E.granulosus s.l. are grouped as E. granulosus sensu stricto (s.s.) (G1 -G3), E. equinus (G4), E. ortleppi (G5), E. canadensis (G6, G7, and G8, G10) and E. felidis [5, 38, 40]. Among them, E. canadensis and E. ortleppi are pathogenic to human, and E. granulosus s.s. responsible for most of human CE in the world [7]. Recently for the first time, E. equinus has recently been reported from humans [41].

Its genotype diversity would implicate pathogenicity, specific hosts, and more importantly, helps designing vaccines and effective medications in different geographical settings [42]. Such studies and related factors provide researchers with information about the state of CE transmission in the country and also a basis for the scope and type of subsequent studies.

Table 2 Information about sequences that used for phylogenetic analysis of cox 1 genes

\begin{tabular}{|c|c|c|c|c|c|}
\hline $\begin{array}{l}\text { Accession number } \\
\text { (cox1) }\end{array}$ & $\begin{array}{l}\text { Genotype of } \\
\text { Echinococcus }\end{array}$ & Reference & $\begin{array}{l}\text { Accession number } \\
\text { (cox1) }\end{array}$ & $\begin{array}{l}\text { Genotype of } \\
\text { Echinococcus }\end{array}$ & Reference \\
\hline MW350093 & G1 & This study & MW350101 & G1 & This study \\
\hline MW350094 & G1 & This study & MW350100 & G6 & This study \\
\hline MW350095 & G1 & This study & MW350092 & G6 & This study \\
\hline MW350096 & G1 & This study & MT535753 & Taenia saginata & $\begin{array}{l}\text { Omondi et al. (2020) } \\
\text { [35] }\end{array}$ \\
\hline MW350097 & G1 & This study & KX685889 & G1 & Shang et al. (2019) [36] \\
\hline MW350098 & G1 & This study & KC415063 & G6 & $\begin{array}{l}\text { Sharma et al. (2013) } \\
\text { [37] }\end{array}$ \\
\hline MW350099 & G1 & This study & $\mathrm{MH} 244469$ & G1 & Neysi et al. (2020) [25] \\
\hline
\end{tabular}




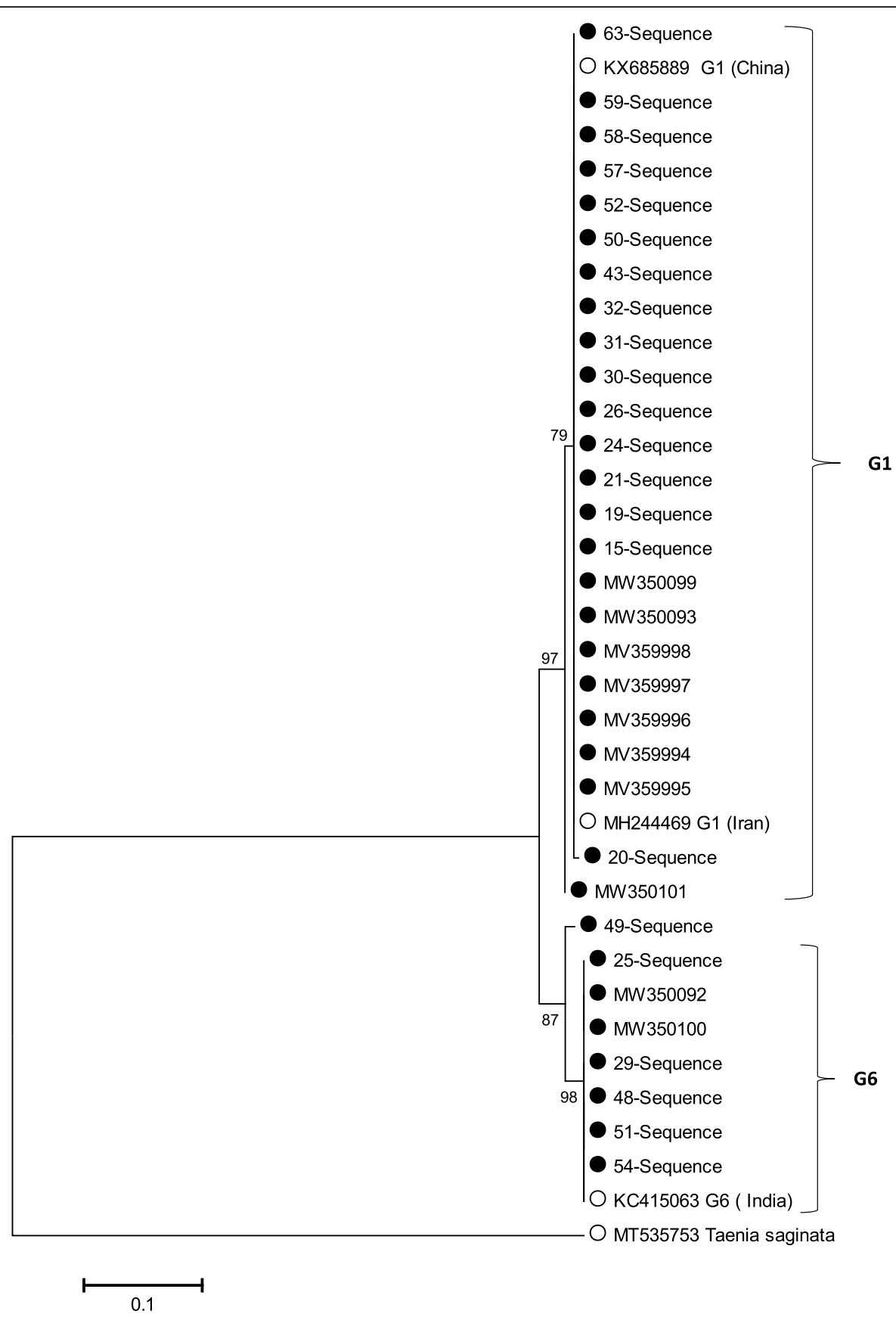

Fig. 4 Molecular phylogenetic tree of mitochondrial cox1 region of E. granulosus s.s. and E. canadensis (G6/G7) isolates from human. Phylogenic analysis was done based on partial cox 1 gene sequences data obtained in the present study and other sequence and species and genotypes of Echinococcus using maximum likelihood method with MEGA 5 software

In the present study, the genotypes of 32 samples were confirmed by sequencing. A total of 24 samples $(75 \%)$ were E. granulosus s.s.(G1-G3) genotype and 8 samples (25\%) were E. canadensis(G6/G7) genotype.

In the study of genotypes of hydatid cysts, using the cox1 gene sequence, the G1 genotype was identified as the dominant genotype of E. granulosus s.l. in human specimens according to other reports from Iran $[4,25$,
26, 29]. The G1 genotype has also been reported in animals including sheep, cattle, goats, and wild boars in Iran [29].

With the analysis of the mitochondrial cox 1 gene, 8 samples (25\%) had the G6/G7 genotype. The presence of E. canadensis (G6) genotype (camel genotype) has previously been reported in domestic animals and humans in different countries including Iran [23, 43-45]. In the 
study of Sadjjadi et al. the G6 genotype was confirmed in the paraffin-embedded tissue of cerebral echinococcal cysts, stating that the G6 genotype has a higher affinity for the human brain than the G1 strain [23].

Our data showed that E. canadensis is responsible for $25 \%$ of human pulmonary CE cases. The active camel-dog cycle of Echinococcus is present in many parts of the country especially camels and sheep breeding areas. The diversity of these results can be explained by the type of studied samples, the differences in the geographical area, and the method used to determine the genotype.

In the present study, the highest level of infection was seen in the age group of 21 to 30 years, and the lowest infection in the age range of 61 to 70 years. No statistical association was observed between the patient's age and the parasite strain. This could be due to the low sample size.

According to previous studies, women are more likely to come in contact with sources of infection, such as dogs, dirt, vegetables, such that the prevalence of CE is more in females than males [29]. However, this is not unique everywhere such that in some areas, males have been the highest involved population [15]. It could be due to the culture and social criteria. In our study from the 32 patients with pulmonary hydatid cysts, 9 patients (28\%) were female and 23 (72\%) were male with a statistically insignificant difference.

In the current study, $18(56 \%)$ of the studied patient had pulmonary hydatid cysts in the left lobe and 14 (44\%) cases had in the right lobe. No significant association was found between the location of the cyst in the lung and the parasite genotype. Our study showed that small hydatid cyst sizes were observed more than other sizes pulmonary CE causes the symptoms related to lung cysts such as cough, chest pain in the early stages of the disease when cysts are small in size, and patients seek treatment. Hence, the disease in the early stages is often stopped with surgery or medication, and the chances of the cyst enlarging and reaching the medium size and large size are reduced. Statistical analyzes showed no significant association between cyst size and parasite strain. However, it is suggested that similar studies be performed on larger scales to determine the genotype of Echinococcus in the province and other areas. Although, it is postulated that some Echinococcus species have preferences for certain organs of their hosts. This can only be investigated if the causative species is identified $[23,24]$. The results of the present work do not show such a correlation.

\section{Conclusion}

E. granulosus s.s. followed by E. canadensis(G6/7) were the most frequent species/genotypes in $\mathrm{CE}$ lungs in southern Iran. However, there was no significant statistical association between cysts' size, location, genotype and, patients' age and gender.
Abbreviations

CE: Cystic echinococcosis; PAIR: Percutaneous Puncture, Aspiration, Injection, and Reaspiration

\section{Acknowledgments}

This work was supported by the office of the Vice Chancellor for Research at Shiraz University of Medical Sciences (SUMS). The authors thank Mrs. Kazemian for her helps.

\section{Authors' contributions}

PM, SMS and BS designed the study; PM and AT developed the surgical technique, performed surgeries; BS and AT collected the samples; BS carried out the tests; PM, SMS, BS and AT analyzed and interpreted the data. AT, BS, PM and SMS drafted the manuscript; all the authors read and approved the final version of the manuscript.

\section{Funding}

SUMS, grant no. 19339.

Availability of data and materials

All data and materials are available upon request.

\section{Declarations}

Ethics approval and consent to participate

This study was approved by the research ethics committee of the Shiraz University of Medical Sciences (ethical code: IR.SUMS.MED.REC.1397.531(.

\section{Consent for publication}

While explaining the study and obtaining consent for participation, participants were told that the results of this research will be published in an international journal.

\section{Competing interests}

The authors declare that they have no competing interests.

\section{Author details}

${ }^{1}$ Department of Surgery, Shiraz University of Medical Sciences, Shiraz, Iran. ${ }^{2}$ Thoracic and Vascular Surgery Research Center, Shiraz University of Medical Sciences, Shiraz, Iran. ${ }^{3}$ Department of Parasitology and Mycology, School of Medicine, Shiraz University of Medical Sciences, Shiraz, Iran.

Received: 12 December 2020 Accepted: 24 May 2021

Published online: 07 June 2021

\section{References}

1. Eckert J, Gemmell M. Meslin Fo-X, Pawlowski Z, organization WH: WHO/OIE manual on echinococcosis in humans and animals: a public health problem of global concern: Paris. World Organisation for Animal Health: France; 2001.

2. da Silva AM. Hydatid cyst of the liver-criteria for the selection of appropriate treatment. Acta Trop. 2003;85(2):237-42. https://doi.org/10.1016/ S0001-706X(02)00271-1.

3. Bhutani N, Kajal P. Hepatic echinococcosis: a review. An Med Surg. 2018;36: 99-105. https://doi.org/10.1016/j.amsu.2018.10.032

4. Romig T, Ebi D, Wassermann M. Taxonomy and molecular epidemiology of Echinococcus granulosus sensu lato. Vet Parasitol. 2015;213(3-4):76-84. https://doi.org/10.1016/j.vetpar.2015.07.035.

5. Nakao M, Lavikainen A, Yanagida T, Ito A. Phylogenetic systematics of the genus Echinococcus (Cestoda: Taeniidae). Int J Parasitol. 2013;43(12-13): 1017-29. https://doi.org/10.1016/j.jpara.2013.06.002.

6. McManus D, Thompson R. Molecular epidemiology of cystic echinococcosis. Parasitology. 2003;127(S1):S37-51. https://doi.org/10.1017/S0031182003003 524.

7. Rojas CAA, Romig T, Lightowlers MW. Echinococcus granulosus sensu lato genotypes infecting humans-review of current knowledge. Int J Parasitol. 2014;44(1):9-18. https://doi.org/10.1016/j.ijpara.2013.08.008.

8. Ebrahimipour M, Sadjjadi SM, Darani HY, Najjari M. Molecular studies on cystic echinococcosis of camel (Camelus dromedarius) and report of Echinococcus ortleppi in Iran. Iran J Parasitol. 2017;12(3):323-31. 
9. Khademvatan S, Majidiani H, Foroutan M, Tappeh KH, Aryamand S, Khalkhali $\mathrm{H}$. Echinococcus granulosus genotypes in Iran: a systematic review. J Helminthol. 2019;93(2):131-8. https://doi.org/10.1017/S0022149X18000275.

10. Sadjjadi SM, Ebrahimipour M, Sadjjadi FS: Comparison between Echinococcus granulosus sensu stricto (G1) and E. canadensis (G6) mitochondrial genes (cox1 and nad1) and their related protein models using experimental and bioinformatics analysis. Comput Biol Chem 2019, 79:103-109, DOl: https://doi.org/10.1016/j.compbiolchem.2019.02.002.

11. Stojkovic M, Weber TF, Junghanss T. Clinical management of cystic echinococcosis: state of the art and perspectives. Curr Opin Infect Dis. 2018; 31(5):383-92. https://doi.org/10.1097/QCO.0000000000000485.

12. Morar R, Feldman C. Pulmonary echinococcosis. Eur Respir J. 2003;21(6): 1069-77. https://doi.org/10.1183/09031936.03.00108403.

13. Arinc S, Kosif A, Ertugrul M, Arpag H, Alpay L, Ünal Ö, et al. Evaluation of pulmonary hydatid cyst cases. Int J Surg. 2009;7(3):192-5. https://doi.org/1 0.1016/j.jjsu.2008.11.003.

14. Ferreres A.R. Management of Thoracic Hydatid Disease and Its Complications. In: Tsoulfas G., Hoballah J., Velmahos G., Ho YH. (eds) The Surgical Management of Parasitic Diseases. Springer, Cham. 2020. p.157-77. https://doi.org/10.1007/978-3-030-47948-0_10.

15. Yalcinkaya I, Er M, Ozbay B, Ugras S. Surgical treatment of hydatid cyst of the lung: review of 30 cases. Eur Respir J. 1999;13(2):441-4. https://doi.org/1 0.1183/09031936.99.13244199.

16. Larrieu E, Frider B, Del Carpio M, Salvitti J, Mercapide C, Pereyra R, et al. Asymptomatic carriers of hydatidosis: epidemiology, diagnosis, and treatment. Rev Panam Salud Publica. 2000;8(4):250-6. https://doi.org/10.1 590/S1020-49892000000900004

17. Nabi MS, Waseem T. Pulmonary hydatid disease: what is the optimal surgical strategy? Int J Surg. 2010;8(8):612-6. https://doi.org/10.1016/j.ijsu.2 010.08.002.

18. Amirian A, Ziaian B, Erfani A, Shahriarirad R, Ranjbar K. Successful Management of a Huge Pulmonary Hydatid Cyst with lung-preserving surgery. Case Rep Surg. 2020;2020:9526406.

19. Dakak M, Caylak H, Kavakli K, Gozubuyuk A, Yucel O, Gurkok S, et al. Parenchyma-saving surgical treatment of giant pulmonary hydatid cysts. Thorac Cardiovasc Surg. 2009;57(03):165-8. https://doi.org/10.1055/s-2008-1 039210.

20. Vasquez J, Montesinos E, Peralta J, Rojas L, DeLaRosa J, Leon J. Need for lung resection in patients with intact or ruptured hydatid cysts. Thorac Cardiovasc Surg. 2009;57(05):295-302. https://doi.org/10.1055/s-0029-11 85604.

21. Abbas N, Addeen SZ, Abbas F, Al Saadi T, Hanafi I, Alkhatib M, et al. Videoassisted thoracoscopic surgery (VATS) with mini-thoracotomy for the management of pulmonary hydatid cysts. J Cardiothorac Surg. 2018;13(1):16.

22. Nakao M, Yanagida T, Konyaev S, Lavikainen A, Odnokurtsev VA, Zaikov VA, et al. Mitochondrial phylogeny of the genus Echinococcus (Cestoda: Taeniidae) with emphasis on relationships among Echinococcus canadensis genotypes. Parasitology. 2013;140(13):1625-36. https://doi.org/10.1017/ S0031182013000565.

23. Sadjjadi S, Mikaeili F, Karamian M, Maraghi S, Sadjjadi F, Shariat-Torbaghan S, et al. Evidence that the Echinococcus granulosus $\mathrm{G} 6$ genotype has an affinity for the brain in humans. Int J Parasitol. 2013;43(11):875-7. https://doi.org/1 0.1016/j.ijpara.2013.06.008.

24. Ito A, Budke CM. The echinococcoses in Asia: the present situation. Acta Trop. 2017;176:11-21. https://doi.org/10.1016/j.actatropica.2017.07.013.

25. Neysi H, Mohammadzadeh T, Sadjjadi SM, Akhavanmoghaddam J, Shamsaei A. Genetic diversity of hepatic/non-hepatic cystic echinococcosis in Baqiyatallah hospital, Tehran. Iran J Parasitol. 2020;15(1):130-7.

26. Moradi M, Meamar AR, Akhlaghi L, Roozbehani M, Razmjou E. Detection and genetic characterization of Echinococcus granulosus mitochondrial DNA in serum and formalin-fixed paraffin embedded cyst tissue samples of cystic echinococcosis patients. PLoS One. 2019;14(10):e0224501. https://doi.org/1 0.1371/journal.pone.0224501.

27. Shahbazi AE, Saidijam M, Maghsood AH, Matini M, Haghi MM, Fallah M. Genotyping of fresh and Parafinized human hydatid cysts using nad1 and cox1 genes in Hamadan Province, west of Iran. Iran J Parasitol. 2020;15(2): 259-65.

28. Sadjjadi SM. Present situation of echinococcosis in the Middle East and Arabic North Africa. Parasitol Int. 2006;55:S197-202. https://doi.org/10.1016/j. parint.2005.11.030.
29. Rokni M. Echinococcosis/hydatidosis in Iran. Iran J Parasitol. 2009:1-16.

30. Thompson RA, McManus DP. Towards a taxonomic revision of the genus Echinococcus. Trends Parasitol. 2002;18(10):452-7. https://doi.org/10.1016/ S1471-4922(02)02358-9.

31. Yanagida T, Mohammadzadeh T, Kamhawi S, Nakao M, Sadjjadi SM, Hijjawi $\mathrm{N}$, et al. Genetic polymorphisms of Echinococcus granulosus sensu stricto in the Middle East. Parasitol Int. 2012;61(4):599-603. https://doi.org/10.1016/j.pa rint.2012.05.014.

32. Deplazes P, Rinaldi L, Alvarez Rojas CA, Torgerson PR, Harandi MF, Romig T, Antolova D, Schurer JM, Lahmar S, Cringoli G, Magambo J, Thompson RC, Jenkins EJ. Global Distribution of Alveolar and Cystic Echinococcosis. Adv Parasitol. 2017;95:315-493. https://doi.org/10.1016/bs.apar.2016.11.001.

33. Bowles J, Blair D, McManus DP. Genetic variants within the genus Echinococcus identified by mitochondrial DNA sequencing. Mol Biochem Parasitol. 1992;54(2):165-73. https://doi.org/10.1016/0166-6851(92)90109-W.

34. Tamura K, Peterson D, Peterson N, Stecher G, Nei M, Kumar S. MEGA5: molecular evolutionary genetics analysis using maximum likelihood, evolutionary distance, and maximum parsimony methods. Mol Biol Evol. 2011;28(10):2731-9. https://doi.org/10.1093/molbev/msr121.

35. Omondi H, Gitau G, Gathura P, Mulinge E, Zeyhle E, Kimeli P, et al. Prevalence and genotyping of Echinococcus granulosus sensu lato from livestock in North-Eastern Kenya. J Helminthol. 2020;94:e205. https://doi. org/10.1017/S0022149X20000899.

36. Shang J, Zhang G, Yu W, He W, Wang Q, Zhong B, et al. Molecular characterization of human echinococcosis in Sichuan, Western China. Acta Trop. 2019;190:45-51. https://doi.org/10.1016/j.actatropica.2018.09.019.

37. Sharma M, Sehgal R, Fomda BA, Malhotra A, Malla N. Molecular characterization of Echinococcus granulosus cysts in north Indian patients: identification of G1, G3, G5 and G6 genotypes. PLoS Negl Trop Dis. 2013; 7(6):e2262. https://doi.org/10.1371/journal.pntd.0002262.

38. Wen H, Vuitton L, Tuxun T, Li J, Vuitton DA, Zhang W, McManus DP: Echinococcosis: advances in the 21st century. Clin Microbiol Rev 2019, 32(2).

39. Ebrahimipour M, Budke CM, Harandi MF. Control of cystic echinococcosis in Iran: where do we stand? Trends in Parasitology; 2020.

40. Hüttner M, Nakao M, Wassermann T, Siefert L, Boomker JD, Dinkel A, et al. Genetic characterization and phylogenetic position of Echinococcus felidis (Cestoda: Taeniidae) from the African lion. Int J Parasitol. 2008;38(7):861-8. https://doi.org/10.1016/j.jpara.2007.10.013

41. Kim H-J, Yong T-S, Shin MH, Lee K-J, Park G-M, Suvonkulov U, et al. Phylogenetic characteristics of Echinococcus granulosus Sensu Lato in Uzbekistan. Korean J Parasitol. 2020;58(2):205-10. https://doi.org/10.3347/ kjp.2020.58.2.205.

42. McManus D. The molecular epidemiology of Echinococcus granulosus and cystic hydatid disease. Trans R Soc Trop Med Hyg. 2002;96(Supplement_1): S151-7.

43. Mwambete KD, Ponce-Gordo F, Cuesta-Bandera C. Genetic identification and host range of the Spanish strains of Echinococcus granulosus. Acta Trop. 2004:91(2):87-93. https://doi.org/10.1016/j.actatropica.2004.04.001.

44. Harandi MF, Hobbs R, Adams P, Mobedi I, Morgan-Ryan U, Thompson R. Molecular and morphological characterization of Echinococcus granulosus of human and animal origin in Iran. Parasitology. 2002;125(4):367-73.

45. Laurimäe T, Kinkar L, Andresiuk V, Haag KL, Ponce-Gordo F, Acosta-Jamett G, et al. Genetic diversity and phylogeography of highly zoonotic Echinococcus granulosus genotype G1 in the Americas (Argentina, Brazil, Chile and Mexico) based on 8279 bp of mtDNA. Infect Genet Evol. 2016;45:290-6. https://doi.org/10.1016/j.meegid.2016.09.015.

\section{Publisher's Note}

Springer Nature remains neutral with regard to jurisdictional claims in published maps and institutional affiliations. 